\title{
Lipid Peroxidation and Nitric Oxide Inactivation in Postmenopausal Women
}

\author{
Isabela Rosier Olimpio Pereira, Marcelo Chiara Bertolami, André Arpad Faludi, \\ Maria Fernanda Campos, Simone Ferderbar, Emersom Silva Lima, José Mendes Aldrighi, \\ Dulcineia Saes Parra Abdalla
}

São Paulo, SP - Brazil

\begin{abstract}
Objective - To assess the effect of endogenous estrogens on the bioavailability of nitric oxide $(\cdot N O)$ and in the formation of lipid peroxidation products in pre-and postmenopausal women.
\end{abstract}

Methods - NOx and S-nitrosothiols were determined by gaseous phase chemiluminescence, nitrotyrosine was determined by ELISA, COx (cholesterol oxides) by gas chromatography, and cholesteryl linoleate hydroperoxides (CE $\left.{ }_{18: 2}-\mathrm{OOH}\right)$, trilinolein $\left(\mathrm{TG}_{18: 2}-\mathrm{OOH}\right)$, and phospholipids (PC-OOH) by HPLC in samples of plasma.

Results - The concentrations of NOx, nitrotyrosine, $\mathrm{COx}, \mathrm{CE}{ }_{18: 2}-\mathrm{OOH}$, and $\mathrm{PC}-\mathrm{OOH}$ were higher in the postmenopausal period (33.8 $\pm 22.3 \mu \mathrm{M} ; 230 \pm 130 \mathrm{nM} ; 55 \pm 19$ $n g / \mu L ; 17 \pm 8.7 n M ; 2775 \pm 460 n M$, respectively) as compared with those in the premenopausal period $(21.1 \pm 7.3 \mu \mathrm{M}$; $114 \pm 41 \mathrm{nM} ; 31 \pm 13 \mathrm{ng} / \mu \mathrm{L} ; 6 \pm 1.4 \mathrm{nM} ; 1635 \pm 373 \mathrm{nM})$. In contrast, the concentration of S-nitrosothiols was lower in the postmenopausal period $(91 \pm 55 n M)$ as compared with that in the premenopausal period $(237 \pm 197$ nM).

Conclusion - In the postmenopausal period, an increase in nitrotyrosine and a reduction of S-nitrosothiol formation, as well as an increase of $\mathrm{COx}, \mathrm{CE}_{18: 2}{ }^{2} \mathrm{OOH}$ and PC-OOH formation occurs. Therefore, $\mathrm{NO}$ inactivation and the increase in lipid peroxidation may contribute to endothelial dysfunction and to the greater risk for atherosclerosis in postmenopausal women.

Key words: menopause, nitric oxide, lipid peroxidation

Instituto Dante Pazzanese de Cardiologia, Faculdade de Ciências Farmacêuticas e Faculdade de Saúde Pública - USP

Mailing address: Dulcineia Saes Parra Abdalla - Av. Prof. Lineu Prestes, 580 - B1. 17 Superior - 05508-900 - São Paulo, SP, Brazil - E-mail: dspa@usp.br English version by Stela Maris C. e Gandour
Cardiovascular diseases are less prevalent in premenopausal women and in those receiving hormone replacement therapy as compared with postmenopausal women and men ${ }^{1}$. This protective effect is attributed to estrogens, and one of the mechanisms of action may be related to the metabolism of plasma lipoproteins ${ }^{2}$.

Estrogens reduce LDL-cholesterol and increase HDLcholesterol ${ }^{3}$. However, these changes in lipid profile only contribute to approximately $25 \%$ of the protective effect of estrogens ${ }^{4}$. Other potential mechanisms of action of estrogens may include protection against LDL oxidation ${ }^{5}$, reduction in lipoprotein(a), potentiation of fibrinolysis ${ }^{6}$, and increase in insulin sensitivity. In the arteries, estrogens improve vasodilating function, decrease calcification, secretion of cell adhesion molecules (E-selectin, ICAM-1, and VCAM-1), and formation of atherosclerotic lesions ${ }^{7}$.

Direct action of estrogens on the arterial wall has also been demonstrated. The administration of estrogens for prolonged periods inhibits the deposition of cholesterol in the arteries and thickening of the intima in monkeys and rabbits fed an atherogenic $\operatorname{diet}^{8}$. However, the mechanisms determining the direct effects of estrogens on the arterial wall have not been completely elucidated. The hemodynamic effects may be partially measured by the activity of estrogens on the synthesis of endothelial nitric oxide ${ }^{9}$. Estrogens have been suggested to possibly improve endothelial function and decrease the risks of atherosclerosis in premenopausal women. Nitric oxide has its bioactivity reduced in postmenopausal women. However, it is not clear whether this occurs due to its lower production by nitric oxide synthase, or whether nitric oxide is inactivated by reaction with the superoxide radical also generated by endothelial cells, forming the peroxynitrite anion (ONOO-), which is a strong oxidizing agent.

Peroxynitrite is decomposed into other reactive oxygen species (fig. 1) ${ }^{10}$ and reacts with tyrosine residues of proteins to form nitrotyrosine ${ }^{11}$. Although little is known 


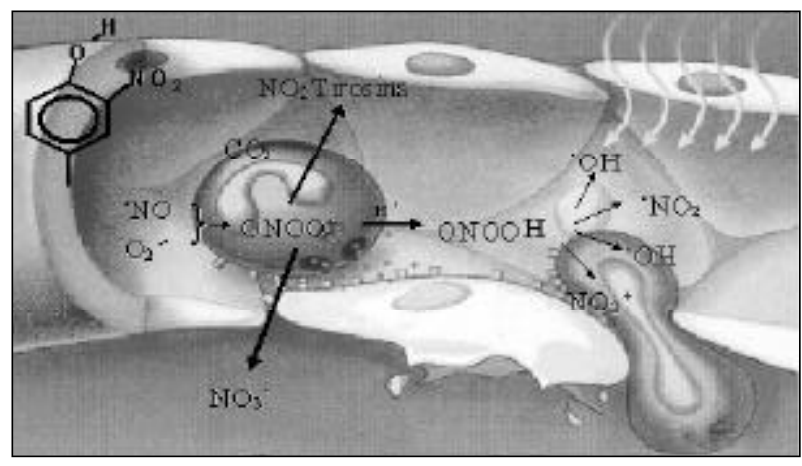

Fig. 1 - Generation of peroxynitrite in the vascular compartment and its decomposition into other oxidizing species. Macrophages and neutrophils may simultaneously generate nitric oxide and superoxide, which interreact to form peroxynitrite. Peroxynitrite may react with tyrosine residues present in proteins forming nitrotyrosine or decomposes into various reactive species of oxygen and nitrogen that promote lipid peroxidation, an increase in vascular permeability, and platelet adhesion.

about the effects of nitration of tyrosines on the in vivo function of proteins ${ }^{12}$, peroxynitrite and its decomposition products induce peroxidation of the membrane lipids ${ }^{13}$ and may initiate lipid peroxidation of human $\mathrm{LDL}^{14}$, causing endothelial lesions and an increase in vascular permeability ${ }^{10}$. Several studies indicate that the endothelium-dependent deficiency in vascular relaxation is associated with inactivation of nitric oxide by formation of peroxynitrite ${ }^{15-17}$.

Nitrogen dioxide $\left(\mathrm{NO}_{2}\right)$ is one of the oxidizing products formed in peroxynitrite decomposition, which rapidly crosses cell membranes due to its high lipophilicity, initiating oxidation of the polyunsaturated fatty acids. Therefore, nitrogen dioxide may take out 1 hydrogen atom from the chains of polyunsaturated fatty acids, initiating the process of lipid peroxidation ${ }^{18}$ (fig. 2). Recently, nitrogen dioxide has also been suggested to form nitrated lipids ${ }^{19}$.

Peroxidation changes in phospholipids, triacylglycerols, and cholesterol esters may occur in reactions promoted by free radicals and by nonradical reactive species, such as peroxynitrite. Lipid hydroperoxides (LOOH) are nonradical intermediates of lipid peroxidation. A cholesterol molecule may also be oxidized with the consequent forma-

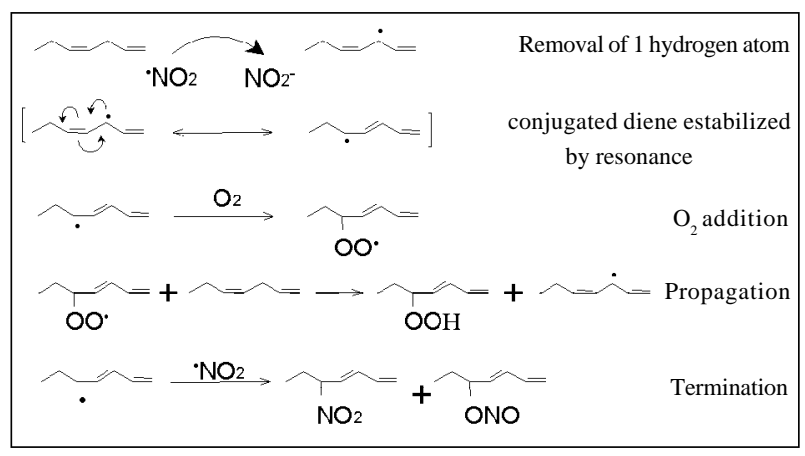

Fig. 2 - Process of lipid peroxidation induced by ${ }^{\circ} \mathrm{NO}_{2}$. The ${ }^{\circ} \mathrm{NO}_{2}$ radical initiates removal of 1 hydrogen atom from a polyunsaturated fatty acid, resulting in a conjugated diene that reacts with an oxygen molecule, forming lipid peroxide. The lipid peroxide removes 1 hydrogen atom from a second fatty acid, forming a lipid hydroperoxide and a second conjugated diene. The conjugated diene may react with the ${ }^{-} \mathrm{NO}_{2}$ radical, forming nitrated products. tion of cholesterol oxides (oxysterols). Cholesterol oxized in position 7 may reduce endothelium-dependent relaxation and nitric oxide production by endothelial cells ${ }^{20}$. High concentrations of cholesterol oxides are found in atherosclerotic arteries and in lipoproteins of hypercholesterolemic patients ${ }^{21}$. Some cholesterol oxides, mainly 7-cetocholesterol, have already been shown to have anti-estrogenic activity $^{22,23}$.

The objective of this study was to assess the effect of endogenous estrogens on the bioavailability of nitric oxide, by determining the concentration of its derivatives, such as NOx (nitrite and nitrate), S-nitrosothiols (which also have vasodilating action) ${ }^{24}$ and nitrotyrosine, and also the formation of lipid hydroperoxides and cholesterol oxides in the plasma of pre- and postmenopausal women.

\section{Methods}

This study was approved by the committees on ethics in research of the institutions involved.

Forty postmenopausal women, with ages ranging from 50 to $65(57.1 \pm 5.6)$ years, and 24 premenopausal women, with ages ranging from 20 to $40(28.1 \pm 5.4)$ years, who were in the middle of their menstrual cycle, were followed up for the minimum period of 1 year. The exclusion criteria were as follows: smoking, uncontrolled hypertension, diabetes, and obesity. After a 12- to 15-hour fasting period, blood was collected in tubes containing EDTA. Plasma was separated and stored in tubes containing antioxidizing agents (butylated hydroxytoluene, BHT $20 \mu \mathrm{M}$ ) and protease inhibitors (aprotinin, $2 \mathrm{mg} / \mu \mathrm{L}$ ), phenylmethyl sulfonyl fluoride (PMSF, $1 \mathrm{mM}$ ), and benzamidine ( $2 \mathrm{mM})$.

The measurements of total plasma cholesterol, LDLcholesterol, HDL-cholesterol and triglycerides were performed with commercial enzymatic methods (BioSytems ${ }^{\circledR}$ ).

The plasma nitrate concentration was measured with the ${ }^{\mathrm{NO}}$ analyzer $\left(\mathrm{NOA}^{\mathrm{TM} 280}\right.$, Sievers Inc., USA). Plasma was previously deproteinized in cold ethanol $(1: 2, \mathrm{v} / \mathrm{v})$, was left resting for 30 minutes at $0^{\circ} \mathrm{C}$, and centrifuged at $10,000 \mathrm{~g}$ for 10 minutes. A $10-\mu \mathrm{L}$ aliquot of the floating material was injected into the $\mathrm{NO}$ analyzer $\left(\mathrm{NOA}^{\mathrm{TM} 280}\right)$. The calibration curve was built with patterns of sodium nitrate. In the $\mathrm{NOA}^{\mathrm{TM} 280}$, plasma nitrate was reduced to ${ }^{\mathrm{NO}}$ with vanadium (III) at $90^{\circ} \mathrm{C}$, and the ${ }^{\circ} \mathrm{NO}$ formed was detected by gaseous phase chemiluminescence after reaction with ozone.

Measurement of total S-nitrosothiols was performed according to Marley et $\mathrm{al}^{25}$ with modifications. Aliquots of $500 \mu \mathrm{L}$ of previously prepared plasma were double injected into the purge vessel of the ${ }^{\circ} \mathrm{NO}$ analyzer $\left(\mathrm{NOA}^{\mathrm{TM} 280}\right.$ ) containing $16 \mathrm{~mL}$ of glacial acetic acid, $4 \mathrm{~mL}$ of KI $50 \mathrm{mg} / \mathrm{mL}$, $1000 \mu \mathrm{L}$ of decanol (antifoam agent), and $400 \mu \mathrm{L}_{\text {of }} \mathrm{CuSO}_{4}$ $200 \mathrm{mM}$ (this solution was exchanged every 8 injections). The calibration curve was built based on S-nitroso-albumin synthesized according to Marley et $\mathrm{al}^{25}$.

Nitrotyrosine concentration in plasma was determined with competitive ELISA. The plates were sensitized with $0.5 \mathrm{mg} / \mu \mathrm{L}$ of nitrated albumin (ALBNO, $100 \mu \mathrm{L}$, approximate 
nitrotyrosine concentration ranging from 40 to $60 \mu \mathrm{M}$ ) diluted in $0.1 \mathrm{M}$ carbonate-bicarbonate buffer in $\mathrm{pH} 9.4$ at $37^{\circ} \mathrm{C}$ overnight. After washing with $200 \mu \mathrm{L}$ of TBS buffer (TRIS-HCl $50 \mathrm{mM}, \mathrm{NaCl} 150 \mathrm{mM}, \mathrm{pH} 7.4$ ) containing $0.05 \%$ Tween 20, the plates were incubated for 2 hours at $37^{\circ} \mathrm{C}$ with $200 \mu \mathrm{L} /$ flask of TBS buffer containing $0.05 \%$ Tween 20 and $5 \%$ skim milk. After a new washing, the plates were incubated with $100 \mathrm{~mL} /$ flask of anti-nitrotyrosine polyclonal antibody (Upstate ${ }^{\circledR}$ biotechnology, diluted 1:1000 in TBS containing $0.05 \%$ skim milk and $0.05 \%$ Tween 20 ) in addition to $100 \mu \mathrm{L}$ of the sample (the plasma samples and nitrated albumin used in the calibration curve were diluted 1:4 in TBS containing $0.05 \%$ milk) for 2 hours at $37^{\circ} \mathrm{C}$. The plates were washed and incubated again with $100 \mu \mathrm{L} /$ flask of conjugate (antirabbit IgG produced in mice conjugated with peroxidase - Stressgen Biotechnologies Corp.) diluted 1:2000 in TBS containing $0.05 \%$ skim milk and $0.05 \%$ Tween 20 for 1 hour at $37^{\circ} \mathrm{C}$. After washing, luminol $(2.3 \mathrm{mM})$, p-iodophenol $(0.9$ $\mathrm{mM})(200 \mu \mathrm{L} / \mathrm{flask})$, and hydrogen peroxide $(3.9 \mathrm{nM})(50 \mu \mathrm{L} /$ flask) were added. The chemiluminescence produced was immediately read, by using the plates of ELISA for chemiluminescence (LumiCount, Packard, Meriden, USA). The concentration of nitrotyrosine in the samples was estimated with the calibration curve built with nitroso-albumin and expressed as equivalents of nitro-ALB. The samples and the calibration curve were tripled. The bovine nitrated albumin used as a pattern to build calibration curves (nitro-ALB; $2-4$ mol of nitrotyrosine/mol of protein) was prepared by adding an alkaline solution of peroxynitrite at a final concentration of $1 \mathrm{mM}$ to a bovine albumin solution (ALB - 1 $\mathrm{mg} / \mu \mathrm{L})$. The solution was then dialyzed overnight in PBS buffer (10 mM of phosphate-buffered sodium, $140 \mathrm{mM}$ of sodium chloride, $2.7 \mathrm{mM}$ of potassium chloride, and $0.02 \%$ sodium azide). The concentration of nitrotyrosine in nitroALB was determined by using the molar extinction coefficient $4300 \mathrm{M}^{-1} \mathrm{~cm}^{-1}$ in $438 \mathrm{~nm}, \mathrm{pH} 9.0$.

The hydroperoxides derived from cholesterol linoleate (CH18:2-OOH), trilinolein (TG18:2-OOH), and phosphatidylcholine $(\mathrm{PC}-\mathrm{OOH})$ were extracted from plasma $(500 \mu \mathrm{L})$ with acetonitrile $(4 \mu \mathrm{L})$ containing $0.02 \%$ BHT in amber tubes by being agitated in vortex for 2 minutes. Afterwards, $4 \mu \mathrm{L}$ of hexane previously treated with Chelex resin were added, and the tubes were agitated in vortex for 2 minutes. Then, the tubes were centrifuged at $2500 \mathrm{rpm}$ for 5 minutes. The floating material containing the cholesterol linoleate hydroperoxides and trilinolein and the deposited material containing the hydroperoxides of phosphatidylcholine were evaporated under nitrogen flow. The residues were resuspended in $100 \mathrm{~mL}$ of $2: 1$ chloroform-methanol. The hydroperoxides were identified with high-performance liquid chromatography with a chemiluminescence detector (HPLC-CL). The device consisted of the following parts: a manual injection system, Perkin-Elmer quaternary pump series 200, postcolumn derivatization system, an injection pump of the derivatization solution (Radpump Series III), and the LC240 fluorescence detector (Perkin-Elmer, software Turbo- chrom Navigator) coupled to a Pentium processor. The derivatization solution was a 1:1 mixture of methanol and borax buffer $\mathrm{pH} 10.0$, containing $1.5 \mathrm{mg}$ of microperoxidase and $177.2 \mathrm{mg}$ of isoluminol, at a rate of $1 \mu \mathrm{L} / \mathrm{min}$. To separate $\mathrm{CH}_{18: 2}-\mathrm{OOH}$ and $\mathrm{TG}_{18: 2}-\mathrm{OOH}$, a Supelco LC18DB column $(25 \mathrm{~cm}, 5 \mu, 4.6 \mathrm{~mm}, 120 \AA)$ was used with the respective precolumn; the $2: 1(\mathrm{v} / \mathrm{v})$ methanol/t-butanol solution at a rate of $1 \mathrm{~mL} / \mathrm{min}$ was the mobile phase. To separate $\mathrm{PC}-\mathrm{OOH}$, the Shim-pack C8 precolumn (Shimadzu Corporation) and the Shim-pack HRC-C8 column (15cm, 4.6mm, Shimadzu Corporation) were used, with the 70:15:15 (v/v) methanol/acetonitrile $/ \mathrm{H}_{2} \mathrm{O}$ at a rate of $1 \mathrm{~mL} / \mathrm{min}$ as the mobile phase. The hydroperoxides were quantified through the relation of the area with a primary pattern of linoleic acid hydroperoxide (13-HPODE - Sigma, St. Louis, MO).

To cholesterol oxides determination, the lipid fraction of the plasma $(500 \mathrm{uL})$ was extracted in chloroform-methanol $(1: 2 \mathrm{v} / \mathrm{v})$ containing $50 \mu \mathrm{l}$ of $5 \alpha$-cholestane (Steraloids, Inc.) $(500 \mathrm{ng} / \mu \mathrm{L})$, which was added to each sample as an internal pattern. The lipid extract was evaporated under a nitrogen current and the residue was redissolved in $1.0 \mu \mathrm{L}$ of toluene:ethyl acetate $(1: 1 \mathrm{v} / \mathrm{v})$. The neutral lipid fraction (triglycerides, cholesterol, and cholesterol oxides) and the polar lipid fraction (phospholipids) were isolated through sequential elution with a column to extract the solid phase (Waters Diol columns) with toluene:ethyl acetate, followed by methanol. The neutral lipid fraction underwent alkaline saponification and methylation with ether diazomethane. The samples were derivatized to trimethylsilylimidazole (TMS) by using $50 \mu \mathrm{L}$ of dimethyl-formamide and $50 \mu \mathrm{L}$ of N,O-bis-trimethylsilyltrifluoroacetamide (BSTFA, Sigma) (1:1). The tubes were sealed, purged with nitrogen, warmed to $80^{\circ} \mathrm{C}$ for 20 minutes, and then transferred to a vial. An aliquot of $1 \mathrm{~mL}$ was injected into the gas chromatograph (CG 6890-Plus - Hewlett Packard) coupled to a HP-5 column (30 $\mathrm{m}$ in length, $0.32 \mathrm{~mm}$ D.I., $0.25 \mu \mathrm{m}$ of filling thickness; Hewlett Packard) and operated with a split ratio of 1:5. Hydrogen was used as a carrying gas at a rate of $5 \mathrm{~mL} / \mathrm{min}$. The injection temperature was $290^{\circ} \mathrm{C}$, and the initial temperature of the column was $260^{\circ} \mathrm{C}$. The race was programmed to remain at the initial temperature for 2 minutes followed by a slope of $5^{\circ} \mathrm{C} / \mathrm{min}$ up to $290^{\circ} \mathrm{C}$. The temperature of the flame ionization detector was $300^{\circ} \mathrm{C}$. The patterns used (Steraloids, Inc.) were as follows: 5 -cholestene-3 $\beta, 7 \alpha$-diol ( $7 \alpha$ $\mathrm{OH})$; 5 -cholestene-3 $\beta, 7 \beta$-diol $(7 \beta-\mathrm{OH})$; cholestan- $5 \alpha, 6 \alpha-$

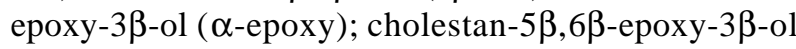
( $\beta$-epoxy); cholestan-3 $\beta, 5 \alpha, 6 \beta$-triol (CT); 5-cholesten-3 $\beta$ ol-7-one (7-Keto); and 5-cholesten-3 $\beta, 25$-diol (25-OH).

The estradiol concentration was determined with the $\mathrm{IMx}^{\circledR}$ System Estradiol kit from Abbott Laboratories.

Data are presented as mean \pm standard deviation. The statistical analysis was performed with the one-way ANOVA and ORIGIN 5.0 software. The correlations were performed with Sigma Stat 1.0 software, Pearson Product Moment method, " $\mathrm{r}$ " " = value of the correlation coefficient, and " $p$ " = descriptive level. A significance level of $\mathrm{P}<0.05$ was adopted. 


\section{Results}

Figure 3 depicts the plasma concentrations of cholesterol, LDL, and HDL in pre- and postmenopausal women. Postmenopausal women (total cholesterol: $281 \pm 42 \mathrm{mg} / \mathrm{dL}$; LDL-cholesterol: $184 \pm 37 \mathrm{mg} / \mathrm{dL}$; HDL-cholesterol: $65 \pm 15$ $\mathrm{mg} / \mathrm{dL}$ ) had a higher concentration of cholesterol as compared with premenopausal women (total cholesterol: $145 \pm 27$ mg/dL; LDL-cholesterol: 83 \pm 24 mg/dL; HDL-cholesterol: $51 \pm 10 \mathrm{mg} / \mathrm{dL}$ ).

Figures 4, 5, and 6 show the plasma concentrations of NOx ( $\mathrm{p}=0.01)$, S-nitrosothiols $(\mathrm{p}<0.0001)$, and nitrotyrosine ( $\mathrm{p}=0.0005$ ), respectively, in the 2 groups analyzed. As compared with premenopausal women $(21.1 \pm 7.3 \mu \mathrm{M} ; 114 \pm 41$ $\mathrm{nM} ; 237 \pm 197 \mathrm{nM})$, postmenopausal women $(33.8 \pm 22.3 \mu \mathrm{M}$; $230 \pm 130 \mathrm{nM} ; 91 \pm 55 \mathrm{nM}$ ) had increased concentrations of NOx and nitrotyrosine and decreased concentrations of Snitrosothiols, respectively.

Figure 7 shows the total concentration of cholesterol oxides in plasma, which was higher in postmenopausal women $(55 \pm 19 \mathrm{ng} / \mu \mathrm{L})$ as compared with that in premenopausal women $(31 \pm 13 \mathrm{ng} / \mu \mathrm{L}, \mathrm{p}=0.0003)$. Figure 8 shows the concentrations of all cholesterol oxides analyzed. Only $\mu$ epoxy-cholesterol showed a significant increase $(\mathrm{p}=0.0003)$ in postmenopausal women $(24 \pm 10 \mathrm{ng} / \mu \mathrm{L})$ as compared with that in premenopausal women $(12 \pm 8 \mathrm{ng} / \mu \mathrm{L})$.

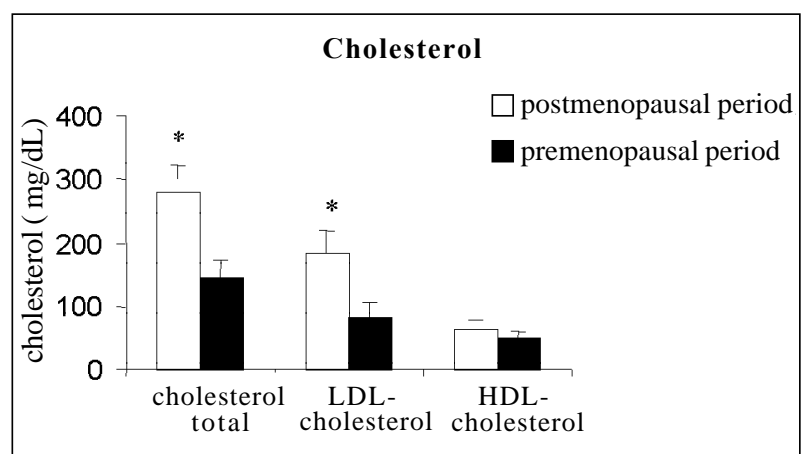

Fig. 3 - Comparison of the concentration of total cholesterol, LDL-cholesterol, and HDL-cholesterol found in the groups of pre- and postmenopausal women. The values are shown as mean \pm standard deviation. $*$ Significant difference between the groups $(\mathrm{p}<0.05)$.

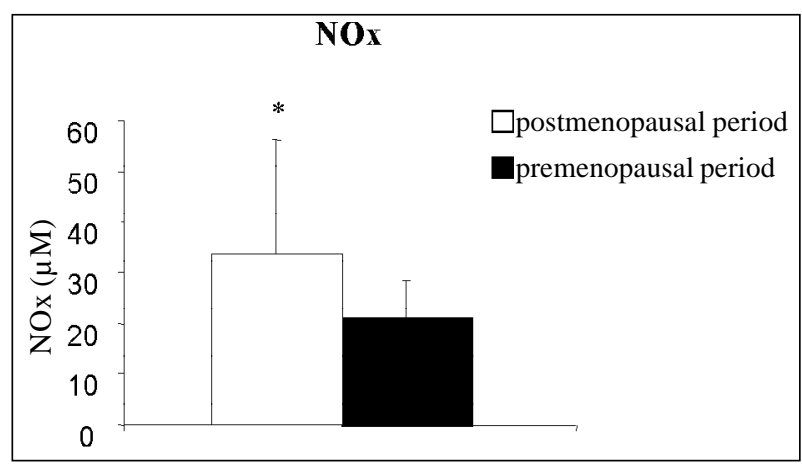

Fig. 4 - Comparison of the NOx concentration found in the groups of pre- and postmenopausal women. The values are shown as mean \pm standard deviation. * Significant difference between the groups $(\mathrm{p}=0.01)$.

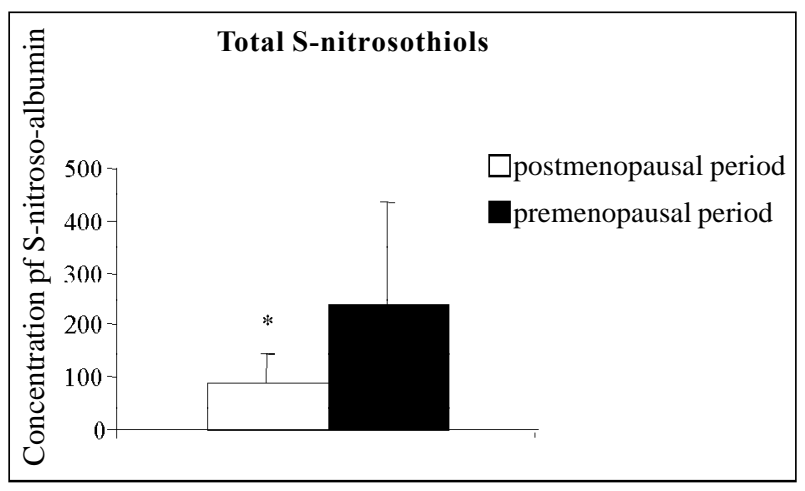

Fig. 5-Comparison of the concentration of total S-nitrosothiols found in the groups of pre- and postmenopausal women. The values are shown as mean \pm standard deviation. * Significant difference between the groups $(\mathrm{p}<0.0001)$.

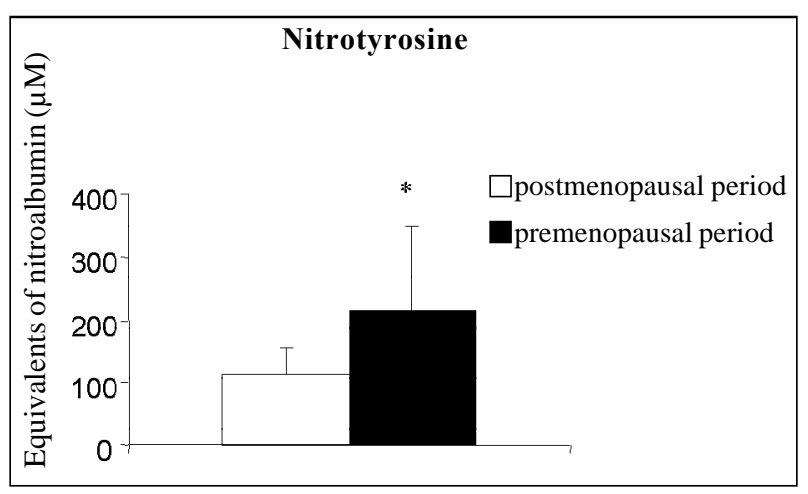

Fig. 6 - Comparison of the concentration of nitrotyrosine found in the groups of preand postmenopausal women. The values are shown as mean \pm standard deviation. * Significant difference between the groups ( $\mathrm{p}=0.0005)$.

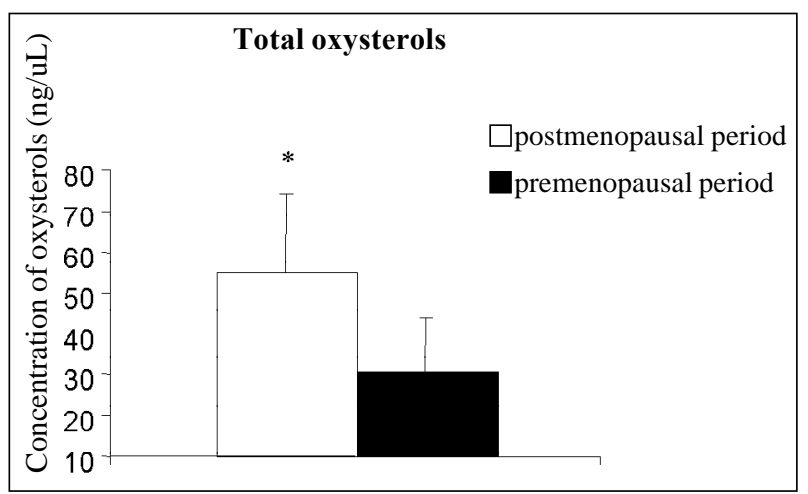

Fig. 7 - Comparison of the concentration of total oxysterols found in the groups of pre- and postmenopausal women. The values are shown as mean \pm standard deviation. * Significant difference between the groups $(\mathrm{p}=0.0003)$.

The concentrations of hydroperoxides of cholesterol esters (17 $\pm 8.7 \mathrm{nM} ; 6 \pm 1.4 \mathrm{nM}$, fig. 9) and of phospholipids $(2775 \pm 460 \mathrm{nM} ; 1635 \pm 373 \mathrm{nM}$, fig. 10) were greater $(\mathrm{p}=0.0007$; $\mathrm{p}<0.0001$, respectively) in the group of postmenopausal women as compared with those in the group of premenopausal women (respectively), indicating greater lipid peroxidation in that group. No difference in triglyceride hydroperoxides $(11 \pm 2.9 \mathrm{nM} ; 12 \pm 4.9 \mathrm{nM})$ was observed between preand postmenopausal women, respectively (fig. 9). 


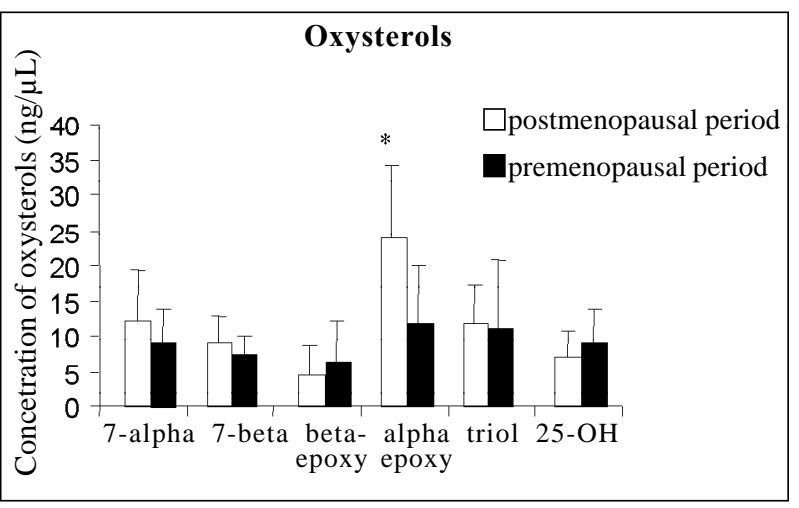

Fig. 8 - Oxysterol profile in the plasma of pre- and postmenopausal women. The values are shown as mean \pm standard deviation. * Significant difference between the groups $(\mathrm{p}=0.0003)$.

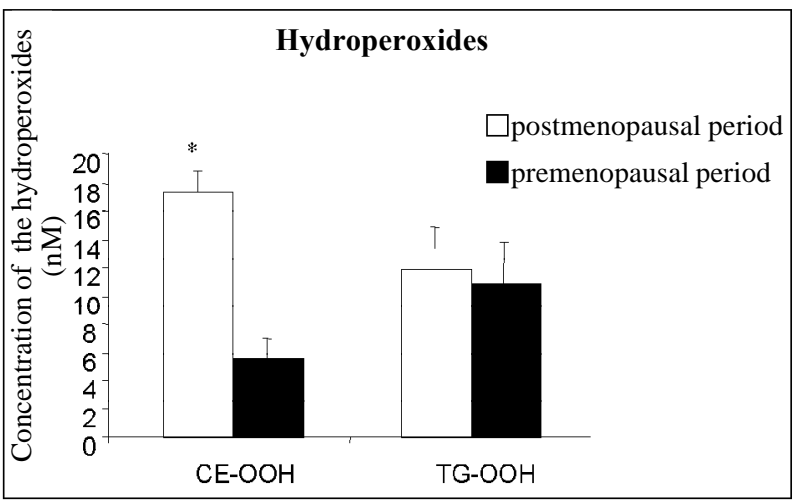

Fig. 9 - Concentration of hydroperoxides of cholesterol esters (CE-OOH) and triglycerides (TG-OOH) in the groups of pre- and postmenopausal women. The values are shown as mean \pm standard deviation. * Significant difference between the groups $(\mathrm{p}=0.0007)$.

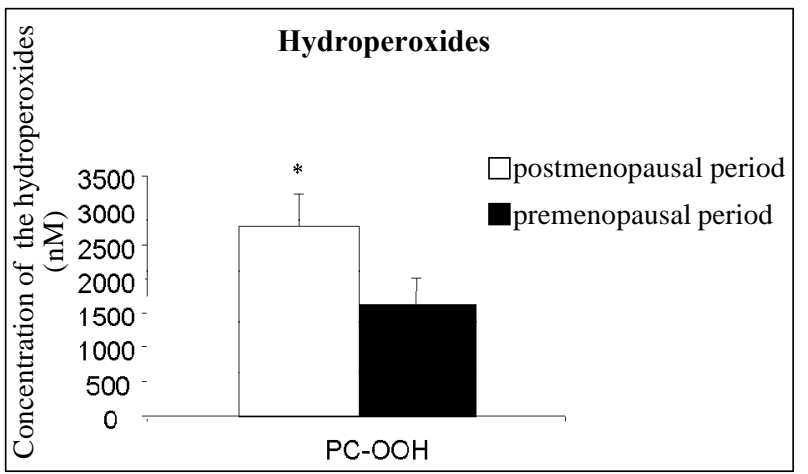

Fig. 10 - Comparison of the concentration of phospholipid hydroperoxides found in the groups of pre- and postmenopausal women. The values are shown as mean \pm standard deviation. * Significant difference between the groups $(\mathrm{p}<0.0001)$.

Figure 11 shows the plasma concentration of estradiol in the 2 groups analyzed $(24 \pm 10 \mathrm{pg} / \mathrm{mL} ; 200 \pm 120 \mathrm{pg} / \mathrm{mL}$, $\mathrm{p}<0.0001)$.

\section{Discussion}

Estrogens increase cholesterol flow from dietary intake to the liver, due to the cholesterol incorporation into

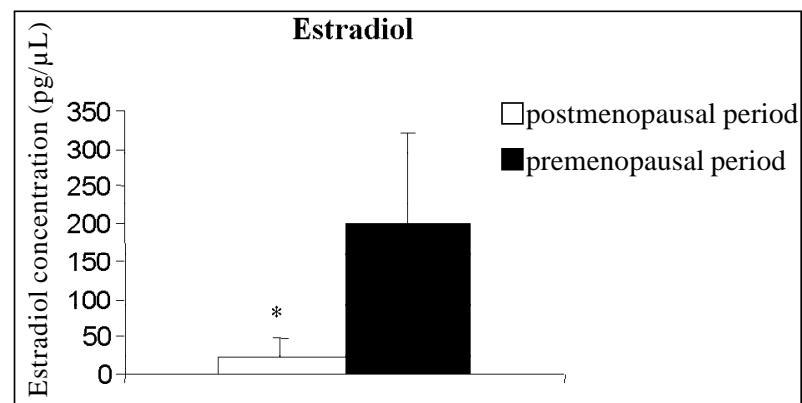

Fig. 11 - Plasma concentration of estradiol found in the groups of pre- and postmenopausal women. The values are shown as mean \pm standard deviation. * Significant difference between the groups $(\mathrm{p}<0.0001)$

chylomicra and remnants of chylomicra. Subsequently, cholesterol flows to the cells of the peripheral tissues, as VLDL and LDL, and returns to the liver via the reverse transportation of cholesterol, as HDL. In liver cells, cholesterol is transformed into bile acids, which, in turn, are excreted in bile. Under the influence of estrogens, the following events may occur: (i) plasma triglycerides increase due to an increase in VLDL production; (ii) LDL concentration is reduced due to an increase in the expression of LDL receptors; (iii) HDL is increased by 2 mechanisms: greater secretion of apolipoprotein A-1, and lower removal of its lipids, because estrogens lead to a reduction in hepatic lipase activity (revised by Zhu et al ${ }^{26}$ ).

In this study, we observed an increase in nitrate concentration associated with a higher cholesterol concentration and with lipid peroxidation in postmenopausal women. Recently, the localization of endothelial nitric oxide synthase (eNOS) in specialized invaginations of the plasma membrane, called caveolae, has been proposed as necessary to the maximal activity of that enzyme ${ }^{27,28}$. Caveolae are highly rich in cholesterol. Caveolin mRNA (protein present in the caveolae and that interacts with eNOS) is up-regulated when the uptake of free cholesterol from LDL to the cell is increased. The regulation of the efflux of free cholesterol via the caveolar path is mediated by caveolin mRNA ${ }^{29}$. Evidence indicates that the increase in caveolin regulation in cells exposed to high levels of LDL-cholesterol results directly from an increase in the transcription of the eNOS gene induced by the higher cellular content of cholesterol ${ }^{30}$. In vitro studies have shown that, when endothelial cells are exposed to low concentrations of oxidized LDL (LDL-ox) for more than 24 hours, an increase in eNOS mRNA is observed, but in high concentrations of LDL-ox, this effect is reversed $^{31,32}$. These observations show the existence of a correlation between the production of nitric oxide, hypercholesterolemia, and lipid peroxidation. The increase in nitrate concentration may result from the increase in eNOS regulation, via caveolin, induced by the increase in the plasma, and consequently caveolar, concentration of cholesterol, and by the increase in LDL-ox concentration.

Barbacanne et al ${ }^{33}$ found an increase in ${ }^{\circ} \mathrm{NO}$ activity induced by estrogens, but observed no change in eNOS gene expression, or in the activity of this enzyme, although 
they detected a lower production of the superoxide radical. The decrease in the generation of endothelium-derived superoxide in response to estrogens could increase the bioactivity of nitric oxide by reducing its inactivation by forming peroxynitrite. Hayashi et al ${ }^{34}$ observed that $17 \beta$ estradiol increases eNOS activity mediated by the receptor; high concentrations of $17 \beta \mu$-estradiol tend to inhibit eNOS activity through a receptor- independent path. $17 \beta$ estradiol was also observed to decrease the release of nitrogen oxides (NOx) produced by nitric oxide synthase (iNOS) in macrophage culture. On the other hand, $17 \beta$ estradiol may act in eNOS by another mechanism, such as activation of the $\mathrm{Ca}^{+2} /$ calmodulin system ${ }^{34}$.

Holm et al ${ }^{35}$ reported that, in ovariectomized rabbits, the antiatherogenic effect of estrogen was eliminated by an endothelial lesion induced with a balloon-catheter (ie, it is endothelium-dependent) and that estrogens increased NOx formation in rabbit plasma, showing that the effect of estrogens in atherosclerosis might relate to greater bioavailability of nitric oxide. The effect of estrogens in reducing cell adhesion molecules and the consequent reduction in adhesion of mononuclear cells to the endothelium may also be mediated by an increase in nitric oxide.

Some studies have shown that the vasodilation produced by $17 \beta$-estradiol is endothelium-independent ${ }^{36}$. Gonzales and Kanagy ${ }^{37}$ observed that N-omega-nitro-arginine, a nitric oxide synthase inhibitor, did not affect vasodilation produced by estrogens in arteries of male rats, both with intact and denuded endothelium. The inhibition of guanylate cyclase did not affect relaxation. Those authors also observed that $17 \beta$-estradiol causes vasodilation by inhibiting $\mathrm{Ca}^{++}$ influx without causing $\mathrm{Ca}^{++}$intracellular release. Therefore, the study showed that $17 \beta$-estradiol causes receptor-mediated vasorelaxation through inhibition of calcium influx, independent of nitric oxide production, of guanylate cyclase stimulation, and of potassium channel activation.

Several pathological conditions, including ischemia/ reperfusion, inflammation, and deficiency in tetrahydrobiopterin, a cofactor for nitric oxide synthesis, may induce the simultaneous production of superoxide $\left(\mathrm{O}_{2}^{-\cdot}\right)$ and ${ }^{*} \mathrm{NO}$ radicals in several tissues ${ }^{10}$, generating peroxynitrite ${ }^{38}$, which has a much greater oxidizing potential than the nitric oxide $\left({ }^{\circ} \mathrm{NO}\right)$ and superoxide $\left(\mathrm{O}_{2}^{-}\right)$radicals alone. Peroxynitrite causes nitration (incorporation of a nitro group - $\mathrm{NO}_{2}$ ) of aliphatic and aromatic residues. Tyrosine residues in proteins are key targets of nitration, mediated by peroxynitrite, and the presence of 3-nitrotyrosine in proteins represents a marker of the endogenous formation of peroxynitrite. The process of nitration involves radicalar mechanisms, in which an electron derived from peroxynitrite attacks the aromatic ring of tyrosine, leading to the formation of a tyrosyl radical, which rapidly combines with nitrogen dioxide $\left({ }^{\circ} \mathrm{NO}_{2}\right)$ to form 3 -nitrotyrosine. In addition to peroxynitrite, another nitration path is the $\mathrm{H}_{2} \mathrm{O}_{2} / \mathrm{NO}_{2}-$ /myeloperoxidase system, which uses nitrite derived from nitric oxide for nitration ${ }^{39}$. $17 \beta$-estradiol has been shown to block the induction of formation of peroxynitrite in cell culture ${ }^{40}$.
Both nitrate and nitrotyrosine concentrations were increased in postmenopausal women. This implies that nitric oxide synthesis was not reduced in postmenopausal women, because nitrate is the major metabolite derived from nitric oxide. In addition, the greater formation of nitrotyrosine indicates possible ${ }^{*} \mathrm{NO}$ inactivation by its reaction with the superoxide radical. Therefore, the product of this reaction, the peroxynitrite anion, or the nitrogen dioxide radical derived from its decomposition would cause nitration of the tyrosine residues of plasma proteins, generating the increase in plasma nitrotyrosine.

Peroxynitrite formation may be associated with estradiol in other pathological conditions. A higher incidence of breast cancer has been associated with exposure to estrogens ${ }^{41,42}$. Estrogen metabolism is altered in most breast cancer tumors. These alterations lead primarily to the formation of catechols, which may generate superoxide ${ }^{43}$. In breast cancer, ${ }^{\circ} \mathrm{NO}$ synthase activity is increased, resulting in increased nitric oxide production, and a consequent increase in peroxynitrite and its decomposition products, which may be related to DNA lesions in breast cancer ${ }^{43}$. On the other hand, the effect of the administration of estrogens on ${ }^{*} \mathrm{NO}$ inactivation has not been clarified. Tamoxifen inhibits ${ }^{*} \mathrm{NO}$ synthase activity and nitrotyrosine formation in the brain of rats ${ }^{44}$. Therefore, further studies assessing the effect of hormone replacement therapy on ${ }^{\circ} \mathrm{NO}$ inactivation are still required.

Nitrosothiols (RSNOs) may be formed by the reaction of ${ }^{\circ} \mathrm{NO}$ with thiol groups ${ }^{25}$ (present in cysteine, homocysteine, and glutathione residues), and its concentration depends on the synthesis of $\mathrm{NO}^{45}$. Nitrosothiols act promoting vasodilation and inhibition of platelet aggregation ${ }^{45}$. Nitrosothiols are considered reservoirs of ${ }^{*} \mathrm{NO}$, and many of their effects may be explained by ${ }^{*} \mathrm{NO}$ release. However, not all biological effects reported for RSNOs are attributed to the $\mathrm{NO}$ donor function of these compounds. Evidence exists that RSNOs by themselves may activate guanylate cyclase, producing vasodilation ${ }^{46}$. Alteration in the vasodilating activity in postmenopausal women may result from the accelerated ${ }^{\mathrm{NO}}$ decomposition or its smaller conversion to RSNOs, or both. The lower concentration of RSNOs in postmenopausal women only confirms the reduced ${ }^{~} \mathrm{NO}$ bioavailability in face of the high nitrotyrosine concentration. $\mathrm{NO}$ synthesized in postmenopausal women may be inactivated prior to the formation of S-nitrosothiols.

The formation of peroxynitrite directly related to the formation of nitrotyrosine may be related to the formation of lipid hydroperoxides by free radicals derived from peroxynitrite decomposition. Because nitric oxide is converted into peroxynitrite, it is not available for the formation of Snitrosothiols in postmenopausal women (fig. 5).

Among the cholesterol oxides analyzed, only $\alpha$ epoxycholesterol was significantly increased in postmenopausal women. That oxide does not inhibit nitric oxide synthesis and does not act on estrogen receptors, but has a cytotoxic effect on endothelial cells ${ }^{47,48}$. Fielding et $\mathrm{al}^{29} \mathrm{re-}$ ported that cholesterol oxides reduce caveolin mRNA, the 
transportation of free cholesterol to cell surface, and free cholesterol efflux. Caveolae are probable intermediates of free cholesterol efflux via HDL ${ }^{29}$. The presence of oxysterols in HDL reduces the capacity of that lipoprotein to stimulate cholesterol efflux ${ }^{32}$. In vitro studies have shown that estradiol is more effective than alpha-tocopherol or betacarotene in inhibiting the formation of cholesterol oxides ${ }^{49}$.

Several studies have shown the in vitro and in vivo antioxidant action of estrogens. The addition of estrogens to a system of LDL oxidation mediated by copper showed an increase in the initiation time of LDL oxidation ${ }^{26}$. Several studies have shown the effect of the administration of estrogens on human LDL oxidation ${ }^{50-52}$. Therefore, the reduced concentration of estrogens could partially explain the increase in lipid peroxidation in postmenopausal women observed in this study.

Other factors could have influenced these results, such as age and the presence of hypercholesterolemia. Because the objective of this study was to compare pre- and postmenopausal women, normalization of the age factor in these 2 groups was not possible. Aging is an important determinant in vascular disease ${ }^{53}$, and some studies have reported a reduction in nitric oxide bioactivity with aging, independent of the sex of the groups studied ${ }^{54,55}$. However, Ohata et al ${ }^{56}$, analyzing the endothelial function in old women (> 80 years), reported that the preservation of endothelial function was associated with estradiol and estriol concentrations. Sader et al ${ }^{57}$ also reported that supplementation with estradiol is associated with an improvement in the endothelial function in healthy young men. Although aging reduces nitric oxide bioavailability, estradiol is also an important factor for endothelial function. The elevated concentration of cholesterol in postmenopausal women may have influenced the results obtained, independent of the plasma concentration of estradiol, although estradiol also affects lipid metabolism ${ }^{58}$. Estradiol deficiency in postmenopausal women is not the only factor responsible for the ele- vation in plasma cholesterol; other factors, such as age, diet, and genetic factors may also influence these results. Wakatsuki et al ${ }^{59}$ observed a strong correlation between estradiol and LDL-cholesterol concentrations in a similar study with pre- and postmenopausal women, suggesting that estrogen plasma concentrations are inversely related to LDL-cholesterol concentration.

Several studies have shown an increase in HDL-cholesterol and a reduction in LDL-cholesterol due to estrogen replacement ${ }^{60}$. Some studies have clearly shown that estrogens reduce total plasma cholesterol ${ }^{61}$ and that hormone replacement therapy may be beneficial for primary prevention of coronary artery disease ${ }^{62}$. However, this protective effect of estrogens has been questioned in some epidemiological studies. The HERS ${ }^{63}$, ERA ${ }^{64}$, and WHIHRT ${ }^{65,66}$ studies have suggested that hormone replacement therapy has no cardioprotective effect in postmenopausal women with coronary artery disease and may even increase the risk of thromboembolism and cardiovascular events. This unexpected effect may have been due to mutations in thrombogenic factors in a subgroup of women ${ }^{67-70}$. Therefore, the cardioprotective effect of estrogens still requires additional studies.

The increase in nitric oxide inactivation due to peroxynitrite formation, the consequent reduction in the formation of S-nitrosothiols, the increase in nitrotyrosine and in lipid peroxidation are factors that can induce a reduction in vasodilation and in the formation of atherosclerotic lesions in postmenopausal women. These results allow for new perspectives for future research concerning the efficacy of hormone replacement therapy on vasodilation and atherosclerosis.

\section{Acknowledgements}

We thank Fundação de Amparo à Pesquisa do Estado de São Paulo (FAPESP) and PRONEX for their financial support.

\section{References}

1. Barret-Connor E, Bush Tl. Estrogen and coronary heart disease in women JAMA $1991 ; 265: 1861-7$

2. Walsh BW, Shiff I, Rosner B, Breenberg L, Ravnikar V, Sacks FM. Effects of postmenopausal estrogen replacement on the concentrations and metabolism of plasma lipoproteins. N Engl J Med 1991; 325: 1196-204.

3. Kannel WB, Hjorthland MC, McNamara PM, Gordon T. Menopause and risk of cardiovascular disease: the Framingham study. Ann Intern Med 1976; 85: 447-52.

4. Stampfer MJ, Colditz BA. Estrogen replacement therapy and coronary heart disease: a quantitative assessment of epidemiologic evidence. Prev Med 1991; 20: 47-63.

5. Sack MN, Rader RJ, Cannon RO III. Oestrogen and inhibition of oxidation of lowdensity lipoproteins in postmenopausal woman. Lancet 1994; 343: 269-70.

6. Koh KK, Mineemoyer R, Bui MN, et al. Effect of hormone-replacement therapy on fibrinolysis in postmenopausal women. N Engl J Med 1997; 336: 683-90.

7. Koh KK, Blum A, Hathaway L, et al. Vascular effects of estrogen and vitamin E therapies in postmenopausal women. Circulation 1999; 100: 1851-7.

8. Adams MR, Kaplan JR, Manuck SB, et al. Inhibition of coronary artery atherosclerosis by 17 -beta estradiol in ovariectomized monkeys. Arteriosclerosis 1990; 10: 1051-7.
9. Hishikawa K, Nakaki T, Marumo H, Suzuki H, Kato R, Saruta T. Up-regulation of nitric oxide synthase by stradiol in human aortic endothelial cells. FEBS Lett 1995; 360: 291-3.

10. Lancaster JJR. Nitric Oxide: Principles and Actions. Academic Press, Inc, 1996.

11. Beckman JS, Ye YZ, Anderson PG, et al. Extensive nitration of phenolics by peroxinitrite. Arch Biochem Biophys 1992; 288: 438-44.

12. Beckman JS, Ye YZ, Anderson PG, et al. Extensive nitration of protein tyrosines in human atherosclerosis detected by immunohistochemistry. Biol Chem Hoppe-Seyler 1994; 375: 81-8.

13. Radi R, Beckman JS, Bush KM, Freeman BA. Peroxynitrite-induced membrane lipid peroxidation: the cytotoxic potential of superoxide and nitric oxide. Arch Biochem Biophys 1991; 288: 481-7.

14. Darley-Usmar VM, Hogg N, O'Leary VJ, Moncada S. The simultaneous generation of superoxide and nitric oxide can initiate lipid peroxidation in human low density lipoprotein. Free Radic Res Commun 1992; 17: 9-20.

15. Dewitt DS, Mathew BP, Chaisson JM, Prough DS. Peroxynitrite reduces vasodilatory responses to reduced intravascular pressure, calcitonin generelated peptide, and cromakalim in isolated middle cerebral arteries. J Cereb Blood Flow Metab 2001; 21: 253-61. 
16. Van Der Loo B, Labugger R, Skepper JN, et al. Enhanced peroxynitrite formation is associated with vascular aging. J Exp Med 2000; 192: 1731-44.

17. Strunk V, Hahnenkamp K, Schneuing M, Fischer LG, Rich GF. Selective iNOS inhibition prevents hypotension in septic rats while preserving endotheliumdependent vasodilation. Anesth Analg 2001; 92: 681-7.

18. Schmitt D, Shen Z, Zhang R, et al. Leukocytes utilize myeloperoxidas e-generated nitrating intermediates as physiological catalysts for the generation of biological active oxized lipids and sterols in serum. Biochem 1999; 38: 16904-15.

19. O'Donnell VB, Eiserich JP, Chumley PH, et al. Nitration of unsaturated fatty acids by nitric oxide-derived reactive nitrogen species peroxynitrite, nitrous acid, nitrogen dioxide, and nitronium ion. Chem Res Toxicol 1999; 12: 83-92.

20. Dekert V, Persegol L, Viens L, et al. Inhibitors of arterial relaxation among components of human oxized low-density lipoproteins: cholesterol derivatives oxized in position 7 are potent inhibitors of endothelium-dependent relaxation. Circulation 1997; 95: 723-31

21. Vaya J, Aviram M, Mahmood S, et al. Selective distribution of oxysterols in atherosclerotic lesions and human plasma lipoproteins. Free Radic Res 2001; 34: 485-97.

22. Murphy PR, Breckenridge WC, Lazier CB. Binding of oxygenated cholesterol metabolites to antiestrogen binding sites from chicken liver. Biochem Bioph Res Commun 1985; 127: 786-92.

23. Hwang PL, Matin A. Interactions of sterols with antiestrogen-binding sites: structural requirements for high-affinity binding. J Lipid Res 1989; 30: 239-45.

24. Myers PR, Minor RLJ, Guerra RJ, Bates JN, Harrison DG. Vasorelaxant properties of the endothelium-derived relaxing factor more closely resemble S-nitrosocysteine than nitric oxide. Nature 1990; 345: 161-3.

25. Marley R, Patel RP, Orie N, Ceaser E, Darley-Usmar V, Moore K. Formation of nanomolar concentrations of S-nitroso-albumin in human plasma by nitric oxide. Free Radic Biol Med 2001; 31: 688-96.

26. Zhu X, Bonet B, Gillenwater H, Knopp RH. Opposing Effects of Estrogen and progestins on LDL oxidation and Vascular Wall Citotoxity: implications for Atherogenesis. Proc Soc Exp Biol Med 1999; 222: 214-21.

27. Forstermann U, Pollock JS, Schmidt HH, Heller M, Murad F. Calmodulindependent endothelium-derived relaxing factor/nitric oxide synthase activity is present in the particulate and cytosolic fractions of bovine aortic endothelial cells. Proc Natl Acad Sci USA 1991; 88: 1788-92.

28. Boje KM, Fung HL. Endothelial nitric oxide generating enzyme(s) in the bovine aorta: subcellular location and metabolic characterization. J Pharmacol Exp Ther 1990; 253: 20-6.

29. Fielding CJ, Bist A, Fielding PE. Caveolin mRNA levels are up-regulated by free cholesterol and down-regulated by oxysterols in fibroblast monolayers. Proc Natl Acad Sci USA 1997; 94: 3753-8.

30. Bist A, Fielding PE, Fielding CJ. Two sterol regulatory element-like sequences mediate up-regulation of caveolin gene transcription in response to low density lipoprotein free cholesterol. Proc Natl Acad Sci USA 1997; 94 : 10693-8.

31. Hirata K, Miki N, Kuroda Y, Sakoda T, Kawashima S, Yokoyama M. Low concentration of oxidized low-density lipoprotein and lysophosphatidylcholine upregulate constitutive nitric oxide synthase mRNA expression in bovine aortic endothelial cells. Circ Res 1995; 76: 958-62.

32. Gesquiere L, Loreau N, Blache D. Impaired cellular cholesterol efflux by oxysterolenriched high density lipoproteins. Free Radic Biol Med. 1997; 23: 541-7.

33. Barbacanne MA, Rami J, Michel JB, et al. Estradiol increases rat aorta endothelium-derived relaxing factor (EDRF) activity without changes in endothelial NO synthase gene expression: possible roule of decreased endothelium derived superoxide anion production. Cardiovasc Res 1999; 41: 21-32.

34. Hayashi T, Yamada K, Esaki T, et al. Endothelium-dependent relaxation of rabbit atherosclerotic aorta was not restored by control of hyperlipidemia: the possible role of peroxynitrite (ONOO-). Atherosclerosis 1999; 147: 349-63.

35. Holm P, Andersen HL, Andersen MR, Erhardtsen E, Stender S. The direct antiatherogenic effect of estrogen is present, absent, or reversed, depending on the state of the arterial endothelium: a time course study in cholesterol-clamped rabbits. Circulation 1999; 100: 1727-33.

36. Barton, M. Vascular effects of estrogens: Rapid actions, novel mechanisms, and potential therapeutic inplications. Chung Kuo Yao Li Hsueh Pao 1999; 20: 682-90.

37. Gonzales RJ, Kanagy NL. Endotelium-independent relaxation of vascular smooth muscle by 17beta-estradiol. J Cardiovasc Pharmacol Ther 1999; 4: 227-234.

38. Huie RE, Padjama S. The reaction of nitric oxide with organic peroxil radicals. Free Radical Res Commun 1993; 18: 195-9.

39. Podrez EA, Scimitt D, Hoff HF, Hazen SL. Myeloperoxidase-generated reactive nitrogen species convert LDL into an atherogenic form in vitro. J Clin Invest Ann Arbor 1999; 103: 1547-60.

40. Wang J, Green PS, Simpkins JW. Estradiol protects against ATP depletion, mitochondrial membrane potential decline and the generation of reactive oxygen species induced by 3-nitroproprionic acid in SK-N-SH human neuroblastoma cells. J Neurochem 2001; 77: 804-11.

41. Henderson BE, Ross RK, Pike MC, Casagrande JT. Endogenous hormones as a major factor in human cancer. Cancer Res 1982; 42: 3232-9.

42. Bernstein L, Ross RK. Endogenous hormones and breast cancer risk. Epidemiol Rev 1993; 15: 48-65.

43. Paquette B, Cantin AM, Kocsis-Bedard S, Barry S, Lemay R, Jay-Gerin JP. In vitro generation of peroxynitrite by 2 - and 4-hydroxyestrogens in the presence of nitric oxide. Chem Res Toxicol. 2001; 14: 547-54.

44. Osuka K, Feustel PJ, Mongin AA, Tranmer BI, Kimelberg HK. Tamoxifen inhibits nitrotyrosine formation after reversible middle cerebral artery occlusion in the rat. J Neurochem. 2001; 76: 1842-50.

45. Eiserich JP, Patel RP, O'Donnell VB. Pathophysiology of nitric oxide and related species: free radical reactions and modification of biomolecules. Molec Aspects Med 1998; 19: 221-357.

46. Stamler JS. S-nitrosothiols and the bioregulatory actions of nitrogen oxides through reactions with thiol groups. Curr Top Microbiol Immunol 1995; 196: 19-36.

47. Lizard G, Gueldry S, Deckert V, Gambert P, Lagrost L. Evaluation of the cytotoxic effects of some oxysterols and of cholesterol on endothelial cell growth: methodological aspects. Pathol Biol 1997; 45: 281-90.

48. Sevanian A, Hodis HN, Hwang J, Mcleod LL, Peterson H. Characterization of endothelial cell injury by cholesterol oxidation products found in oxidized LDL. J Lipid Res 1995; 36: 1971-86.

49. Ayres S, Tang M, Subbiah MT. Estradiol-17beta as an antioxidant: some distinct features when compared with common fat-soluble antioxidants. J Lab Clin Med. 1996; 128: 367-75.

50. Brussard HE, Leuven JAG, Kluft C, et al. Effect of 17 beta-estradiol on plasma lipids and LDL oxidation in postmenopausal woman with tipe II diabetes mellitus. Arterioscler Thromb Vasc Biol 1997; 17: 324-39.

51. Mcmanus JM, Eneny JM, Thompson W, Young IS. The effect of hormone replacement therapy on the oxidation of low-density lipoprotein in postmenopausal woman. Atherosclerosis 1997; 135: 73-81.

52. Mckidnney KA, Duell PB, Wheaton DL, et al. Differential effects of subcutaneous estrogen and progesterone on low-density lipoprotein size and susceptibility to oxidation in postmenopausal rhesus monkeys. Fertil. Steril 1997; 68: 525-30.

53. Toprakci M, Ozmen D, Mutaf I, et al. Age-associated changes in nitric oxide metabolites nitrite and nitrate. Int J Clin Lab Res 2000; 30: 83-5.

54. van der Loo B, Labugger R, Skepper JN, et al. Enhanced peroxynitrite formation is associated with vascular aging. J Exp Med. 2000; 192: 1731-44.

55. Hamilton CA, Brosnan MJ, McIntyre M, Graham D, Dominiczak AF. Superoxide excess in hypertension and aging: a common cause of endothelial dysfunction. Hypertension. 2001; 37(2 Part 2): 529-34.

56. Ohta H, Komukai S, Sugimoto I, et al. Effect of a HMG-CoA reductase inhibitor combined with hormone replacement therapy on lipid metabolism in Japanese women with hypoestrogenic lipidemia: a multicenter double-blind controlled prospective study. Maturitas 1998; 29: 163-71.

57. Sader MA, McCredie RJ, Griffiths KA, Wishart SM, Handelsman DJ, Celermajer DS. Oestradiol improves arterial endothelial function in healthy men receiving testosterone. Clin Endocrinol (Oxf) 2001; 54: 175-81.

58. Zhu XD, Bonet B, Knopp RH. Estradiol 17b inhibition of LDL oxidation and endothelial cell cytotoxity is opposed by progestins to different degrees. Atherosclerosis 2000; 148: 31-41.

59. Wakatsuki A, Sagara Y. Lipoprotein metabolism in postmenopausal and oophorectomized women. Obstet Gynecol. 1995; 85: 523-8.

60. Paganini-Hill A, Dworsky R, Krauss RM. Hormone replacement therapy, hormone levels, and lipoprotein cholesterol concentrations in elderly women. Am J Obstet Gynecol 1996; 174: 897-902.

61. Farish E, Spowart K, Barnes JF, et al. Effects of postmenopausal hormone replacement therapy on lipoproteins including lipoprotein(a) and LDL subfractions. Atherosclerosis 1996; 126: 77-84.

62. Barrett-Connor E, Grady D. Hormone replacement therapy, heart disease, and other considerations. Annu Rev Public Health 1998; 19: 55-72.

63. Hulley S, Grady D, Bush T, et al. Randomized trial of estrogen plus progestin for secondary prevention of coronary heart disease in postmenopausal women. Heart and Estrogen/progestin Replacement Study (HERS) Research Group. JAMA 1998; 280: 605-13.

64. Herrington DM, Reboussin DM, Brosnihan KB, et al. Effects of estrogen replacement on the progression of coronary-artery atherosclerosis. N Engl J Med 2000; 343: 522-9.

65. McGowan JA, Pottern L. Commentary on the women's health initiative. Maturitas 2000; 34: 109-12.

66. Design of the Women's Health Initiative clinical trial and observational stud. The Women's Health Initiative Study Group. Control Clin Trials 1998; 19: 61109.

67. Glueck CJ, Wang P, Fontaine RN, Tracy T, Sieve-Smith L, Lang JE. Effect of 
exogenous estrogen on atherothrombotic vascular disease risk related to the presence or absence of the factor V Leiden mutation (resistance to activated protein C). Am J Cardiol 1999; 84: 549-54.

68. Glueck CJ, Wang P, Fontaine RN, Sieve-Smith L, Lang JE. Interaction of estrogen replacement therapy with the thrombophilic $20210 \mathrm{G} / \mathrm{A}$ prothrombin gene mutation for atherothrombotic vascular disease: a cross-sectional study of 275 hyperlipidemic women. Metabolism 2001; 50: 360-5
69. Psaty BM, Smith NL, Lemaitre RN, et al. Hormone replacement therapy, prothrombotic mutations, and the risk of incident nonfatal myocardial infarction in postmenopausal women. JAMA 2001; 285: 906-13

70. Gardemann A, Lohre J, Katz N, Tillmanns H, Hehrlein FW, Haberbosch W. The $4 \mathrm{G} 4 \mathrm{G}$ genotype of the plasminogen activator inhibitor $4 \mathrm{G} / 5 \mathrm{G}$ gene polymorphism is associated with coronary atherosclerosis in patients at high risk for this disease. Thromb Haemost 1999; 82: 1121-6.

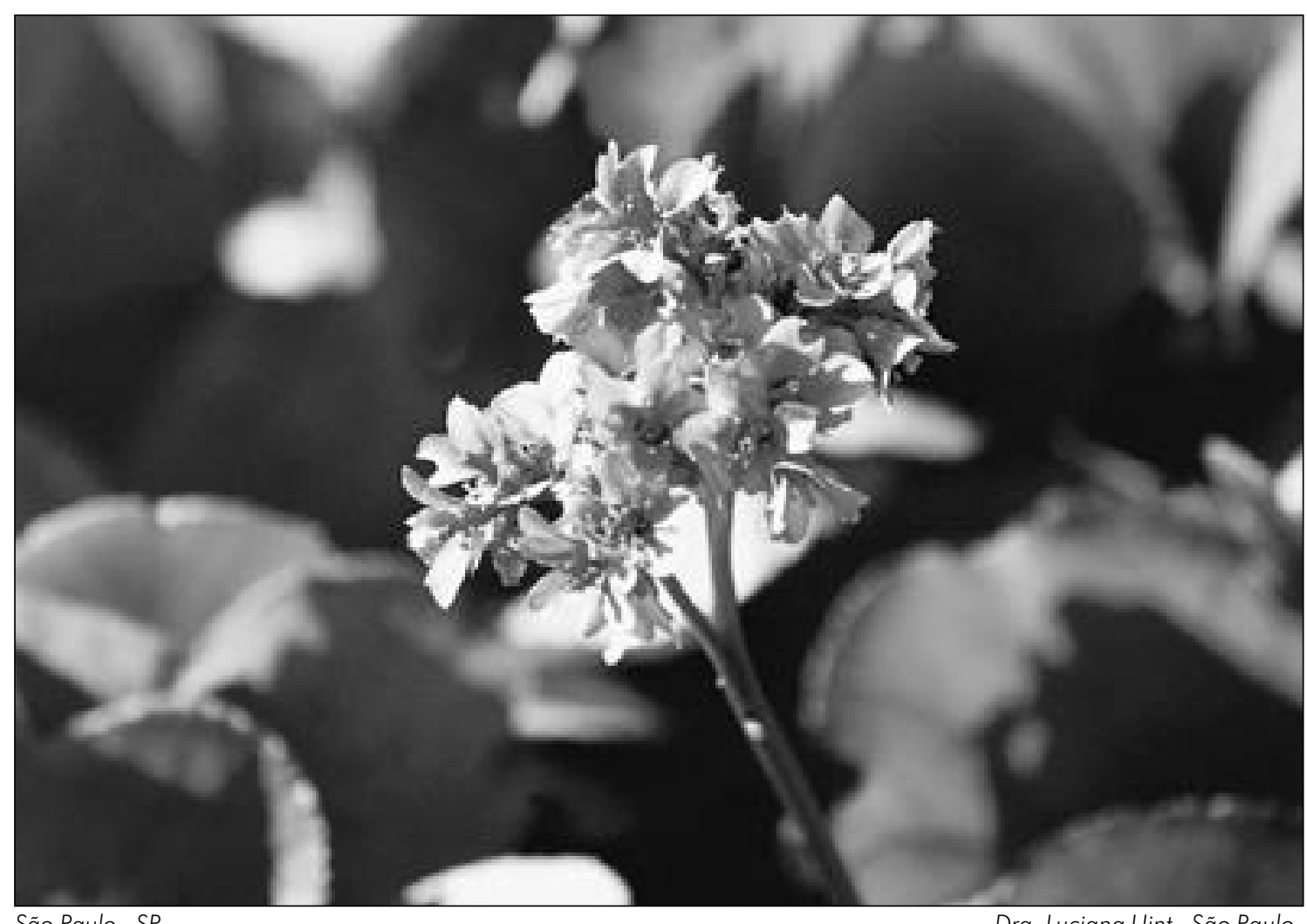

Editor da Seção de Fotografias Artísticas: Cícero Piva de Albuquerque

Correspondência: InCor - Av. Dr. Enéas C. Aguiar, 44 - 05403-000 - São Paulo, SP - E-mail: delcicero@incor. usp.br 